\title{
LA UTOPÍA DE UN IMPERIO CATÓLICO UNIVERSAL. ANÁLISIS ICONOGRÁFICO E ICONOLÓGICO DEL FRONTISPICIO DE UNA CRÓNICA AMERICANA DEL SIGLO XVI: ELEGÍAS DE HOMBRES ILUSTRES DE INDIAS DE JUAN DE CASTELLANOS
}

Olaya Sanfuentes

Pontificia Universidad Católica de Chile

\section{RESUMEN}

A través del siguiente artículo queremos desvelar los elementos iconográficos e iconológicos del emblema que ilustra el frontispicio de la crónica Elegía de hombres ilustres de Indias, de Juan Castellanos. Esta composición comparte un espíritu utópico propio de aquellos que se identificaban con la corona española y soñaban con un imperio católico universal. El deseo de mejorar el mundo a finales del siglo XVI en Europa, incluye a América. Una América que fue inventada para que en ella pudieran proyectarse los sueños e ideales utópicos europeos.

Palabras clave: América, Imperio Católico, Juan de Castellanos, utopía, descripción

\section{ABSTRACT}

Our aim in this paper is to highlight the iconographic and iconological elements of the emblem illustrating the frontispiece of Elegies of Illustrious Men of the Indies, a chronicle by Juan de Castellanos. Its composition reflects the selfsame utopian spirit of those who identified themselves with the Spanish crown and who dreamed of a universal Catholic empire. The desire in late 16th-century Europe to improve the world encompassed America, an America that was invented so that utopian European dreams and ideals could be projected on to it.

Keywords: America, Catholic empire, Juan de Castellanos, utopia, description

\section{Introducción}

Una alegoría del imperio católico universal ilustra el frontispicio de la obra Elegías de hombres ilustres de Indias de Juan de Castellanos (1522-1607). Creemos que esta imagen puede interpretarse como un juego' de espejos con vocación utópica: la España contra reformista se mira en el espejo de la ya descubierta América y en el ejercicio de mirarse y volver a mirar, se encuentra primero consigo misma, al tiempo que sueña con un mundo perfecto y justo en esas tierras nuevas. Este mundo perfecto es aquel en que lo nuevo y lo conocido se unen por la fe cristiana a través del dominio de la corona de los Austrias. 
A través del siguiente artículo queremos develar los elementos iconográficos e iconológicos de ese emblema que comparte un espíritu utópico propio de aquellos que se identificaban con la corona española y soñaban con un imperio católico universal (Fig. 1).

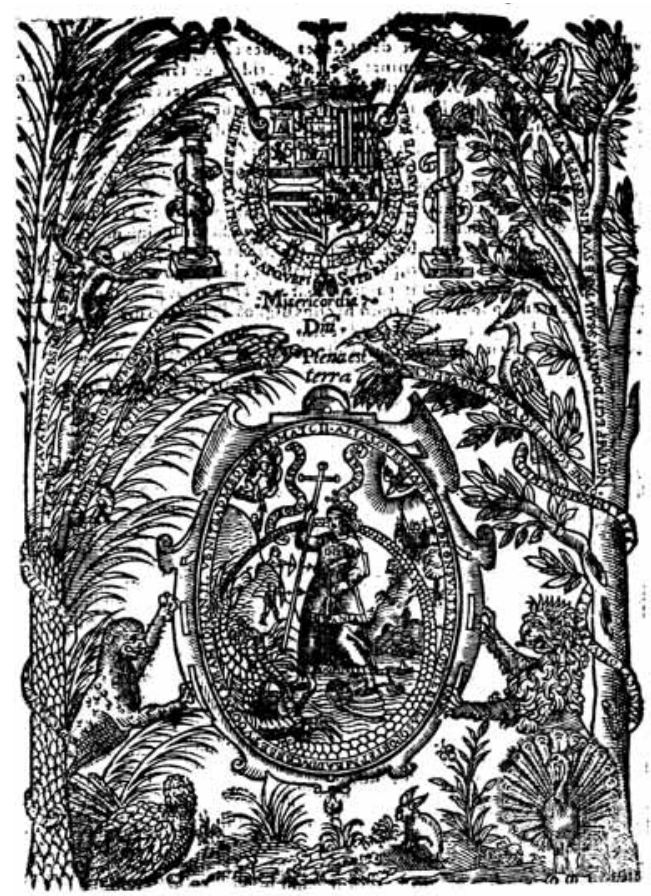

Fig. 1. Juan de Castellanos, Primera Parte de las Elegías de varones ilustres de Indias, Casa de la viuda de Alonso de Gómez, Madrid, 1589

El siglo XVI se inaugura, entre otros eventos, con el nacimiento de uno de los personajes más importantes de la historia europea. Nacía Carlos $V$, quien luego se convertiría en el monarca de un gran imperio. Cuando Carlos tenía apenas 16 años, Cristóbal Colón ya había cruzado varias veces el Atlántico develando al mundo europeo unas tierras jamás antes contempladas por europeo alguno. Hernán Cortés había conquistado México y mostraba, por su parte, unas civilizaciones que nada tenían que envidiar a las del viejo mundo. La ciudad lacustre de Tenochtitlán fue comparada con Venecia y el imperio azteca había logrado un importante nivel de civilización. En este contexto es que Carlos $V$ capitalizaría el emblema de los Pilares de Hércules con la inscripción Plus Ultra, que reemplazaría al tradicional Non Plus Ultra. Si bien antes se pensaba que las orillas del Estrecho de Gibraltar no eran traspasables porque el Océano Atlántico era un mar desconocido y plagado de monstruos, donde no había nada más allá (Non Plus Ultra) y estaba reservado solamente para aquellos que se atrevieran a desafiar el designio de los dioses, el año 1492 demostró que había algo más allá de los temidos Pilares de Hércules.

Carlos $\vee$ tomaría este mito clásico y lo capitalizaría visualmente utilizando este emblema como su propio distintivo, imagen que reflejaba no solamente la influencia clásica en el ambiente renacentista de la época, sino también el espíritu desafiante e imperialista que animaría a los Habsburgo. La realidad resultaba muy auspiciosa, pues era la primera vez en la historia que un imperio se construía en las dos orillas del océano².

Todo esto ocurría hacia 1516, fecha que coincide, asimismo, con la publicación de Utopía de Tomás Moro, obra que se imagina -en un mundo sin locación específica- la mejor de las repúblicas y su gobierno ideal ${ }^{3}$. No es extraño, entonces, que el descubrimiento de las nuevas tierras americanas y Utopía, se relacionen en las mentes de los contemporáneos y en las posteriores interpretaciones que se han hecho de la obra. Muchos vieron en América una naturaleza y una humanidad no corrompidas por la civilización y, por tanto, una alternativa a la vida europea de entonces. Quienes apoyan esta teoría señalan que fue precisamente América la que habría inspirado la obra de Tomás Moro. Como argumentos se dice que Moro habría dejado constancia de su entusiasmo por las noticias americanas; que habría conocido la Cosmografía de Martin Waldseemüller y la obra de Pedro Mártir de Anglería; que tuvo conversaciones con John Rastell -su cuñado-, quien viajó a Norteamérica en 1517. La razón más crucial, sin embargo, es que el narrador del viaje, Rafael Hitlodeo, se identifica a sí mismo como un marinero que habría hecho tres viajes con Américo Vespucio4.

Otros vieron en América una suerte de espacio vacío donde podían llevarse a cabo los sueños de una sociedad mejor y podía establecerse un gobierno perfecto. Algunos incluso han interpretado la obra como la expresión del imperialis- 
mo naciente en el siglo XVI5. En la obra "Utopía y poder en Europa y América", los autores argumentan que el surgimiento de la utopía en Europa no se entiende sin el estado de ánimo que América insufló en los europeos a partir del año $1492^{6}$. La historia de Europa en general debe comprenderse a la luz de la idea de América y de las relaciones dialécticas entre Europa y el Nuevo Mundo.

Para Beatriz Fernández Herrero la utopía es un móvil en el descubrimiento de América desde los inicios y no solo una consecuencia del hallazgo. Colón habría partido con la idea mesiánica de encontrar el paraíso terrenal?. Pero, por otra parte, veremos que en la época había asimismo un afán por apoderarse del mundo y hacer de él un lugar perfecto con el que muchos soñaban.

Felipe II heredaría el espíritu y el cometido carolino en lo que a las aspiraciones dinásticopolítica se refiere y abogaría por la españolización de la dinastía:. Un importante testimonio material y visual de esta iconografía de propaganda imperial lo constituye una medalla del año 1549 de Leone Leoni. La doble imagen de Carlos V y su hijo muestra las aspiraciones del primero respecto al segundo, los dos retratados en el anverso de la medalla. En el reverso está la corona imperial, los pilares de Hércules con la inscripción Plus Ultra y el toisón de oro?. Los afanes imperialistas de los Austrias estaban envueltos de catolicismo.

El espíritu político-religioso emanado de la corona se permeó en muchas manifestaciones culturales literarias y visuales de la época. Es el caso de la obra de Juan de Castellanos, Elegías de varones ilustres de Indias. El texto y la imagen del frontispicio tienen elementos que comulgan entre ellos y con las ambiciones de la corona, demostrando el espíritu de época y el carácter oficial de la obra, surgida de las imprentas reales. Las ideas generales que animan Utopía, de Tomás Moro, deben de haber llegado hasta Juan de Castellanos, hombre erudito que muestra lecturas clásicas y variadas en su obra. Se sabe, por los estudios que hicieran José Antonio Maravall y Francisco López Estrada, que Utopía se leyó en España desde fechas muy tempranas, por lo que las ideas ahí contenidas tienen que haber llegado a la corte y a Juan de Castellanos. Con- temporáneo a Castellanos, Francisco Quevedo, tras leer el texto del canciller inglés, considera que Utopía no es la descripción de un sueño que no se puede hacer realidad, sino más bien propuestas a tomar en consideración para ejercer un buen gobierno ${ }^{10}$. Agustín Redondo, quien nos proporciona esta información, agrega que la utopía puede presentar no solamente aspectos políticos, sino también económicos, sociales o religiosos, aspectos todos que estaban en la obra de Tomás Moro"1.

Una vez en España, las ideas de Utopía habrían cobrado un carácter especial. En otros países la Utopía resultaba de una experiencia literaria, mientras que en España las ideas utópicas procedían de una experiencia vital ${ }^{12}$. Cuando se encuentran con las inimaginables maravillas del Nuevo Mundo, los juegos de espejos se ven condicionados por la novedad específica que América proporcionaba. Otorgaremos algunos datos que nos permitan conocer al autor y su obra, para luego detenernos en la imagen visual que hemos descrito desde el comienzo como utópica.

\section{Juan de Castellanos y su obra}

La obra Elegías de hombres ilustres de Indias de Juan de Castellanos fue escrita en la ciudad de Tunja -Reino de Granada- y publicada en Madrid el año 1589 "en casa de la viuda de Alonso Gómez, impresor de su majestad"13. El libro trata de los muy ilustres hombres que habrían acompañado a Colón y de todos los que le siguieron en la empresa de conquista de estas tierras para la santa fe y la Corona de Castilla. Lo escribe para dejar constancia de las increíbles hazañas de estos hombres y para que sus descendientes los guarden en la memoria.

La obra ha sido estudiada y valorada tanto desde la historiografía como desde la literatura, en la medida que ha sido utilizada como rico testimonio de los procesos de la conquista y como ejemplo significativo del barroco americano ${ }^{14}$.

Su relato está impregnado de una vocación historiográfica porque narra hechos que el autor vivió, al tiempo que recurre a diversos informantes para relatar acontecimientos del pasado. Hay episodios en que el autor llega a incluir hasta seis versiones del mismo hecho para mostrar su interés en la verdad. 
El lugar desde el que se sitúa para elegir sus narraciones y los actores que conforman su relato es el de un súbdito leal a la corona con una arraigada fe cristiana. Este ánimo se traduce en una descripción de opuestos en que muestra la distancia entre el mundo cristiano europeo por un lado y el de los indígenas americanos infieles por el otro; entre el civilizado imperio español y el salvaje y bárbaro mundo americano. La solución inevitable a esta distancia dicotómica es la conquista y la evangelización.

Al tiempo que el texto presenta la situación y solución a esta distancia, el autor va dejando constancia del asombro que siente al enfrentarse a esta naturaleza nueva, mostrando nuevamente el recurso de la contraposición, esta vez entre la naturaleza nueva y la ya conocida.

Esta forma de conocer y reconocerse en el otro haciendo un uso retórico de la diferencia es lo que se conoce como la admiratio. En la reacción ante la diferencia con el otro, el admirarse puede adquirir connotaciones positivas o negativas. Bernal Díaz del Castillo se admira frente a la organización de la ciudad de Tenochtitlán, al tiempo que llaman negativamente su atención los sacrificios humanos de los aztecas. En definitiva, es un sentimiento ante lo nuevo, lo excepcional, lo inesperado, lo extremado, lo sublime o simplemente lo que es difícil de entender, que se traduce en un método para conocer la diferencia. El admirarse frente al mundo circundante es el primer paso en el proceso cognitivo. Luego se descubre lo que esa cosa diferente es y se le distingue de las demás. La dimensión retórica de la admiratio pasa a la político-persuasiva en el momento que persigue mover al receptor a través de la búsqueda de diferencias y semejanzas con su propio mundo. Y, por tanto, cimentando el conocimiento del Nuevo Mundo, se establecen las herramientas para luego pensar el mundo ideal de un imperio capaz de incluir el Viejo y el Nuevo Mundo's.

Desde los estudios literarios, la obra de Juan de Castellanos ha sido estudiada como perteneciente al género de la épica, una representación y una alabanza del poder que tuvo un gran prestigio en la época del renacimiento en España y fuera de ella. Para Lara Vilá y Tomás, la épica es una interpretación que se impuso a lo largo de la tradición occidental a partir de la Eneida de Virgilio. La celebración de Roma y Augusto de la Eneida tiene influencia en la épica española del siglo XVI y en la historiografía y el arte de la época "que hicieron de España la sucesora del Imperio Romano y de estos dos soberanos (Carlos $\mathrm{V}$ y Felipe II) los legítimos herederos de sus emperadores" ${ }^{\prime 1}$.

Sin negar la pertenencia a este género, queremos agregar que esta obra y su frontispicio quieren mostrar el sueño universal de un mundo mejor.

\section{La alegoría}

La imagen que tenemos al frente se inserta en un marco contextual amplio cual es el descubrimiento, conquista y colonización del Nuevo Mundo durante el siglo XVI, con los problemas y posibilidades que esto trajo aparejados. El contexto general nos habla de una descripción de la novedad americana en términos visuales, utilizando el discurso de la comparación. Comparación visual, en este caso.

Las primeras crónicas de descubrimiento del Nuevo Mundo abundan en descripciones de las nuevas tierras, sus especies de flora y fauna, así como del hombre que las habita. Para poder dejar constancia de la maravilla o estupefacción frente a un mundo no descrito por textos clásicos ni por la Biblia, el europeo recurre a la exageración, a la interpretación acomodaticia, a la proyección de sus propios miedos y expectativas y a la comparación con lo ya conocido. La comparación y la analogía eran los métodos privilegiados para el conocimiento del mundo y para poder insertar la naturaleza y el hombre nuevos en un esquema mental seguro y conocido. Esta práctica funcionaba como modelo en la literatura de viajes más expandida en aquel entonces. En las páginas de las crónicas abundan expresiones tales como "parecido a lo nuestro" o "diferente a lo nuestro", entendiendo que lo europeo era la medida de todas las cosas. Definiendo lo ajeno con relación a lo europeo es que Rodrigo de Albornoz compara el río de higueras con el Rin. Otros relacionan el volcán Popocatépetl con el monte Etna y Bernal Díaz del Castillo dice que Cholula se parece de lejos a Valladolid. Tenochtitlán es, según Cortés, tan 
grande como Sevilla y Córdoba. Bartolomé de las Casas compara a La Española con Inglaterra. La búsqueda de similitudes con lo conocido podía llegar a verdaderos extremos, como cuando Hernán Cortés le escribe a Carlos V desde Mesoamérica "que no hay diferencia de esta tierra con España"17. Esta expresión encierra un juicio de valor: al asemejarse a España, lo descrito merece aceptación porque se acerca a lo normal, lo familiar, lo racional. Para Antonello Gerbi, en este acto de reconocimiento de la semejanza en la diferencia hay un acto de conquista y de subyugación ${ }^{18}$. Otros cronistas, pondrán el énfasis en las diferencias del Nuevo Mundo con el ya conocido, donde este último es el que articula el discurso. Así como en el texto el autor contrapone lo conocido con lo nuevo, en la imagen visual hay también interés por mostrar los opuestos, la contraposición entre dos mundos. El extrañamiento que suscita lo nuevo provoca este "juego de perspectivas" 19 .

En este contexto es que, de alguna forma, se puede leer visualmente esta imagen. Hay aquí dos mundos que se contraponen: el de la derecha y el de la izquierda. El de la derecha es el Viejo Mundo que, si bien tiene su centro articulador en Europa, logra incorporar a África y Asia como mundos conocidos y ya aprehendidos desde los criterios europeos. América, en cambio, confronta a Europa con una alteridad radical. $\underline{\text { llanos }}$

El frontispicio de la obra de Juan de Caste-

El viejo mundo a la derecha, se compara con el nuevo mundo a la izquierda y en esta comparación, lo tradicional conocido establece su estatus de superioridad frente a las nuevas tierras. Las especies americanas están ahí mostrando ser una suerte de hermanas menores de las antiguas: el león melenudo del costado derecho, aparece como un león sin melena en el izquierdo. Debe ser un puma, especie americana diferente al león. El soberbio pavo real se despoja de su pluma abierta en el pavo de la izquierda. Años después de nuestra imagen, la idea de inferioridad de la naturaleza americana perduraba. Para el conde de Buffon, (comienzos del siglo XVIII) las especies americanas eran inferiores a las europeas por las diferentes condiciones climáticas que soportaban, entre las que la humedad producía defectos. La pobreza de las tierras americanas, colaboraba también a que los animales terminaran corrompiéndose y que especies como los cuadrúpedos fueran más pequeños que su contraparte del Viejo Mundo. A este respecto, Buffon nombra al tapir como el mamífero más corpulento de América.

Ahondando ahora en el significado más específico que tendrían todos y cada uno de los símbolos de esta alegoría, vemos lo siguiente (Fig. 2): 


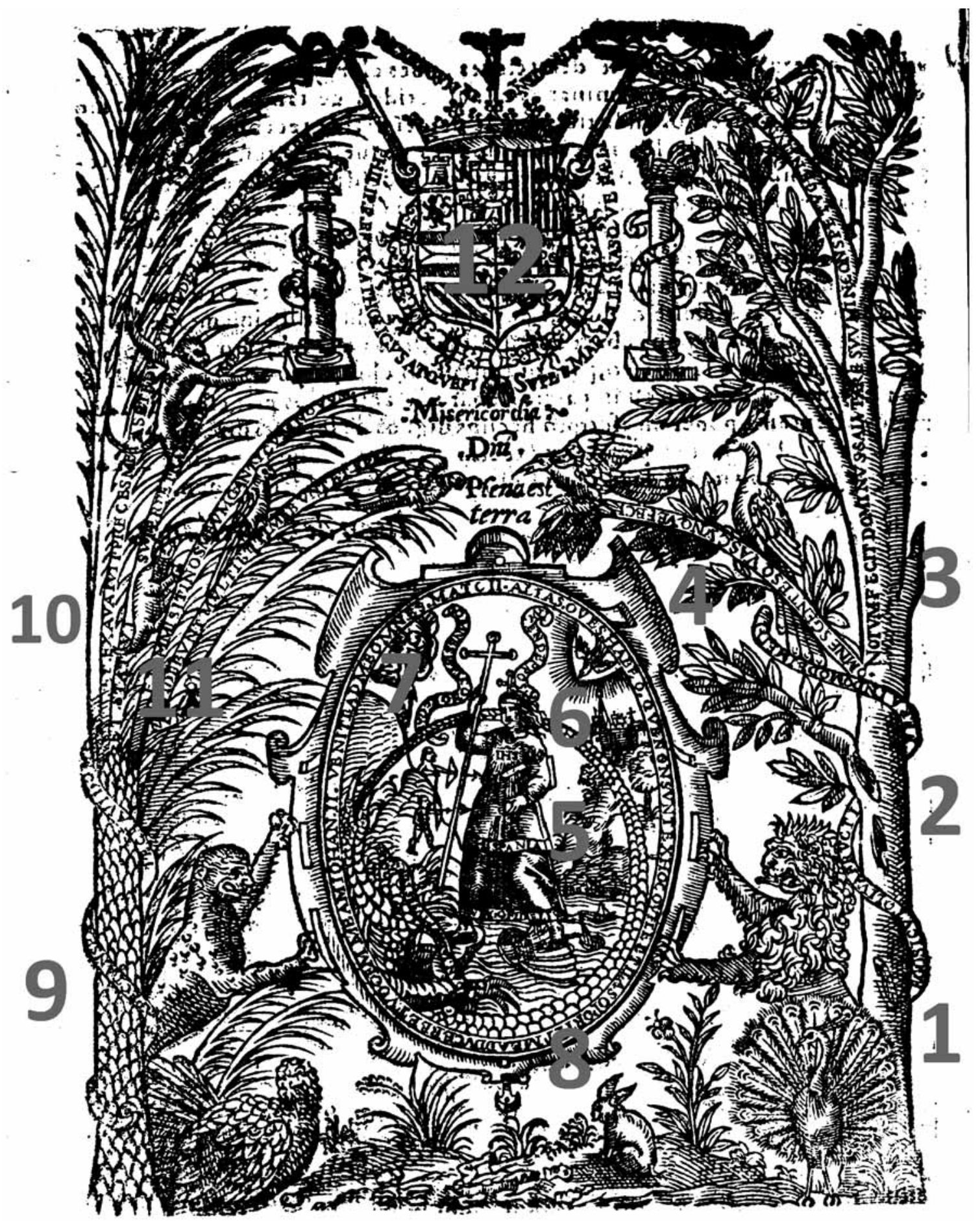

Fig. 2. Juan de Castellanos, Primera Parte de las Elegías de varones ilustres de Indias, Casa de la viuda de Alonso de Gómez, Madrid, 1589. Frontispicio con numeración de símbolos. 


\section{1-2 "EGO [AUTEM] SICUT OLIVA FRUCTIFE- RA IN DOMO DEI"}

Salmo 51, versículo 10.

"Yo, [al contrario], a manera de un fértil olivo, subsistiré en la Casa de Dios"

\section{NOTVM FECIT DOMINUS SALUTARE} SVVM IN CONSPECTV GENTIVM. P.97

Salmo 98, 2.

"El señor ha hecho conocer su Salvador [ha manifestado su justicia] a los ojos de las naciones"

\section{4. "OMNES GENTE QUAMCUSQUE FECISTI"}

Salmo 85, versículo 9.

"Las naciones todas cuantas criaste"

\section{HISPANIA VIRGO FIDELIS}

Hispania virgen fiel

\section{DAN IO}

Daniel Yo

\section{DIRUPTUS EST DRACO}

Daniel 14,26

"mataré al dragón"

\section{INTENDE PROSPERE}

Salmo 44,5

"camina, avanza"

\section{OMNES IST CONGREGATI}

Isaías 49, 18

"Todas estas gentes se han congregado"

8. MARC II. ALIAS OVES HABEO, QUAE NON SUNT EX HOC OVILI: ET ILLAS OPORTET ME ADDUCERE, ET VOCEM MEAM AUDIENT"

Juan 10,16

"Tengo también otras ovejas que no son de este aprisco, las cuales debo yo recoger y oirán mi voz"

13. MISERICODIA DIU [Domini] PLENA EST TERRA

Salmo 32, 5

"toda la tierra está llena de la misericordia del señor"
9. EXPECTANS EXPECTAVI DOMINUM

Salmo 39, 2

"Con ansia suma estuve aguardando al Señor"

11. ET INMISIT IN OS MEUM CANTICUM NOVUM VIDEBUNT MULTI ET TIMEBUNT

Salmo 39, 4

"Pusóme en la boca un cántico nuevo"

"Verán esto muchos y temerán [al señor]"

10. ET EXAUDIVIT PRECES MEAS ET EDUXIT ME DE LACU MISERIAE

Salmo 39, 3

"y escuchó benignamente mis suplicas y sacóme del lago de la miseria"

12. Pilares: PLUS ULTRA

"Más Allá"

Bajo del escudo: PHILIP 2 REX CATHOLICVS ATQVE PI[US] /SVPERMARIA TERRASQUE EAE [ECCLESIAE] DE [DEFENSOR]

Traducción: "Felipe II, rey católico y piadoso /Por los mares y las tierras de la Iglesia defensor" [Defensor de la Iglesia por los mares y tierras]

Arriba de la cruz: "REX REGUM ET DOMINUS DOMINANTIUM"

Apocalipsis cap. 199 versículo 15-16

"Rey de reyes y señor entre los señores" 
A la izquierda están las siguientes especies: un pavo, un puma, un pequeño animal que parece un tapir pero que, probablemente por estar en el árbol, sea una iguana; hay también tres papagayos y un mono. El pavo americano en espacio mexicano fue encontrado por los colonizadores europeos en estado silvestre desde el sur de Canadá hasta Centroamérica. Los mexicas llamaban guajalote a un ave comestible parecida a la gallina. Los españoles le pusieron el explícito nombre de "gallo de papada" y debe de haber sido bien considerado entre los indígenas y los extranjeros ya que hay registro de que se incluyó entre los primeros y más grandiosos banquetes del Nuevo Mundo. Antes de la aparición en esta imagen, el pavo ya había sido retratado en una escultura de bronce por Giovanni de Bologne el año 1567. En su Histoire de la nature des Oyseux, Paris 1555, P. Bellon, ya informado de las noticias sobre tierras americanas y su fauna, también lo representa en un grabado en que incluye a tres pavos. El mono de esta imagen, debe ser un "mono araña", endémico de América.

El pájaro que más se representa para el espacio americano es el papagayo. Su imagen proliferó desde muy temprano en las representaciones visuales del Nuevo Mundo, convirtiéndose en un elemento distintivo de las tierras descubiertas. En las primeras representaciones cartográficas, está ahí el papagayo para denotar el exotismo y según algunos, relacionando estas tierras con el paraíso terrenal. Quizás el grabado de Adán y Eva de Alberto Durero, en que aparece un papagayo, pueda ser interpretado como la influencia del exotismo del paisaje americano en la representación del Paraíso. A pesar de que este animal se relacionaba también con Oriente, Durero tuvo la oportunidad de apreciar los objetos, animales, plantas y hombres americanos que llevó Hernán Cortés para desplegar delante de Carlos V. Entre todos los especímenes, sabemos que había papagayos. El papagayo era un símbolo complejo que podía aludir a lo oriental, a lo exótico y a climas de temperaturas tropicales ${ }^{20}$. América cabía en este esquema perfectamente. El papagayo de estas latitudes queda también plasmado en una de las galerías vaticanas, donde el tema del paraíso, con su belleza y abundancia, es un recordatorio permanente de la existencia de lugares idílicos.
En el lado derecho de la composición está el Viejo Mundo. Un conejo está justo debajo del medallón y en relación con él para denotar la presencia de Hispania. Un poco más a la derecha hay un pavo real, también conocido como "pavo real de la India", animal asiático admirado en Europa desde la Antigüedad. Está representado con las plumas abiertas en todo su esplendor. Un poco más atrás, un león de perfil sosteniendo el escudo como en la tradición heráldica. Si vamos subiendo por el olivo, nos encontraremos con diversas aves como un cuervo, una suerte de capón, perdiz o paloma y más arriba todavía en el árbol, una garza.

El mundo vegetal está enmarcando la composición. La naturaleza bíblica de las plantas del viejo mundo contrasta con el exotismo de las especies vegetales americanas.

Las plantas de la derecha son olivos. Para el mundo americano se eligen palmáceas, de las cuales en América había muchos géneros y especies. Aparecen descritas desde las primeras crónicas colombinas, que por su similitud con la palmera datilera mediterránea los españoles las denominan simplemente como dátiles. A las muchas especies de palmáceas americanas, hay que agregar los diversos nombres que los indígenas utilizaban para identificarlas, lo que produjo muchas confusiones en la época.

En este caso, entonces, los árboles están en el emblema mostrando los recursos naturales ${ }^{21}$. Los científicos europeos reparaban en las propiedades medicinales de estas plantas que podían colaborar a paliar o sanear enfermedades europeas. Un nombre relevante en este proceso es el de Nicolás Monardes. Aunque nunca salió de España, quedó impresionado con las plantas que llegaban desde América y prometían ser un remedio para toda clase de enfermedades y heridas. La obra de Monardes fue ampliamente conocida tanto en España como en el resto de Europa ${ }^{22}$.

En el medio de la composición están las figuras que median entre el mundo de la derecha y el de la izquierda. De abajo hacia arriba tenemos un medallón de importante tamaño que muestra las dos orillas separadas por el Océano y un personaje con túnica, bastón y libro que las une poniendo un pie en cada territorio. Tras mucho hurgar y pensar a la luz del espíritu de la obra 
en general, del emblema en particular y de alguna iconografía circundante (el conejo en este caso), hemos concluido que esa figura es Hispania. Hispania es el nombre que los romanos tenían para la península ibérica. Existen diferentes teorías respecto al origen del nombre y sus interpretaciones, habiendo una que colabora en la explicación de nuestra imagen visual: es la que explica a Hispania como tierra de conejos. Según Benjamín García Hernández cuniculus se consignó ya en la Antigüedad como nombre hispano para designar al conejo, especie que abundaba en la península y en las Baleares. El diccionario de Corominas y Pascual decía que "consta por declaraciones de Plinio y de Elanio que así el animal como su nombre fueron de origen hispánico en la Roma antigua". En este contexto es que creemos que el conejo que está justo debajo del medallón es un icono que colabora en la identificación de la doncella como Hispania. Pareciera haber otra razón para pensar que el personaje en cuestión es Hispania: Según Vilá, la figura de Hércules remite también a la historia mítica de España ya que, según la leyenda, este héroe fue su fundador y su hijo Hispán, su primer soberano23. En este escenario, Carlos V descendería de Hércules a través de la persona de Hispán.

En alguna cartografía del siglo XVI -derivada de Münster y resignificada luego por Matías de Quad-, España había mostrado su importancia, adaptando la geografía de Europa a una mujer coronada cuya cabeza es Hispania ostentando la corona imperial ${ }^{24}$. Hay aquí una idea de superioridad europea que resuena en la obra que estamos trabajando y que quedó prontamente fijada en el Tratado de Iconología de Cesare Ripa. A la idea romana de superioridad política, Ripa agrega la de verdadera y única religión, mejor que todas las otras religiones restantes 25 .

Esta imagen, por tanto, era capaz de albergar el milenario sueño romano de un imperio universal al que se le agrega el espíritu de cruzada religiosa de los Austrias.

El mar que separa las dos orillas es un mar que debe ser navegado por barcos europeos para poder unir lo que estaba separado. La metáfora del navegante es una referencia epocal. El navegante es el que incluyó a América en el imaginario europeo y tiene que jugar un rol en este sueño de una Europa y América unidas por el poder político y religioso de los Austria.

El territorio del lado derecho, al cual Hispania da la espalda, es el Viejo Mundo, representado por castillos y construcciones que denotan civilización, vida en ciudades y en policía. El territorio de la izquierda, en cambio, donde Hispania está colocando su pie derecho y a donde se dirige es el Nuevo Mundo. La ciudad del Viejo Mundo contrasta con el indio desnudo y flechero que simboliza estas nuevas tierras. Estos indígenas habían sido descritos desde el primer documento de Cristóbal Colón anunciando su descubrimiento en la carta que escribiera a Luis Santángel en 1493 y su descripción sería retomada por varios cronistas posteriores -entre ellos Gonzalo Fernández de Oviedo que los describe como "indios flecheros"-logrando consolidar una imagen mental reduccionista de los habitantes de estas tierras. La desnudez denota su inferioridad y la actitud belicosa justificaría la guerra justa.

En el sector americano hay un gigantesco reptil que se come la cola y que lleva una inscripción en latín. La serpiente es símbolo del pecado y colabora en el vocabulario visual de justificación de la evangelización.

Al dar la vuelta la hoja que contiene la imagen descrita, nos encontramos con las siguientes palabras que sellan nuestra comprensión del asunto:
La virgen guerrera declara: el reino hispano
Es la orilla del mar océano y el dragón mismo
Esta serpiente enorme rodea el orbe por ambos lados
Uniendo la cabeza con la cola a través de largos estrechos
En consecuencia, cualquier cosa que suceda, lo que contiene uno y otro mundo,
Gran Felipe, servirá a tu imperio ${ }^{26}$

Arriba del medallón descrito está el escudo de los Austrias y a sus lados los Pilares de Hércules. Domina la escena una cruz que de alguna forma está también unida a través de inscripciones con los árboles de los lados derecho e izquierdo, probablemente sugiriendo una historia de la salvación que une las maderas de la cruz y de los árboles de la Tierra. Con esto, tanto el Viejo Mundo como América estarían destinados a recibir el Evangelio y a formar parte de un mismo proyecto. 


\section{Análisis iconológico}

Detrás de la propuesta de este nuevo orden utópico ordenador del espacio imperial bajo la corona de los Austria, estaba el deseo milenario de unidad imperial, así como la necesidad coyuntural de restituir una unidad perdida tras la reforma protestante y la nueva posibilidad de proyecto global que propiciaba la evangelización de América. Una unidad territorial, política y religiosa de todas las tierras heredadas y conquistadas construida desde el intelecto y proyectada propagandísticamente al resto de la sociedad a través de la imagen visual. Una utopía de una sociedad ideal.

Para poder unir lo que está separado, hay que relevar la distancia, a través de un juego de oposiciones significativas en una suerte de juego de espejos.

La imagen del espejo para mirarse en el otro y así determinar la propia identidad había sido utilizada en la historia de Occidente a partir de los griegos, que se miraron en el "espejo deformante" del bárbaro asiático, una figura creada por el griego para que les sirviera de contraste en el ejercicio de legitimar su propia identidad ${ }^{27}$. El concepto de bárbaro irá traspasando los siglos para ir, en cada época, encarnando los temores y prejuicios del europeo. Para el griego el bárbaro era aquel que no se expresaba con fluidez en griego. A esta "deficiencia" se le agregarían luego matices de índole política y moral surgidas en el contexto de las guerras de griegos con otros pueblos. Para los romanos, bárbaros serían todos aquellos que no formaban parte del imperio. Grandes grupos de bárbaros eran los celtas, los godos y los germanos. Para la Cristiandad posterior que unía Imperio y religión, al otro lado del espejo estarían los disidentes y los paganos. Cuando no se podía convertir pacíficamente a los pueblos paganos, quedaba siempre el recurso de la guerra santa.

Cuando los europeos descubren las nuevas tierras americanas, el indígena y su entorno servirán entonces de espejo a Europa. Y al fundir la tradición clásica con la judeo cristiana, se clasifican a los pueblos en cristiano-civilizado y pagano-bárbaro. A pesar de haber encontrado civilizaciones avanzadas como la mesoamericana y la andina, los europeos consideraban inferiores a aquellos pueblos que no profesaban lo que ellos consideraban la verdadera religión. Esta inferioridad fue incluso legitimada por los naturalistas europeos muchos años después. En el siglo XVIII aplicaron a la especie humana una óptica similar a la que utilizaban para clasificar a los animales. Linneo se contentó con señalar cuatro grandes grupos humanos, uno por cada continente y los caracterizó de la siguiente forma: los europeos se regían por leyes; los americanos por costumbres; los asiáticos por la opinión y los africanos actuaban en forma arbitraria ${ }^{28}$. Los animales y plantas, por el influjo del medio en los seres vivos, también eran entonces inferiores en América respecto a Europa.

Como consecuencia de la idea europea respecto al indígena como inferior y objeto de protección (una vez ya subyugado por la fuerza) es la actitud paternalista y la necesidad europea de proteger y tutelar al indígena. Bajo el eufemismo de la encomienda o transferencia que la Corona otorga a un particular el deber de tutela, defensa y evangelización de un grupo de indígenas ${ }^{29}$, muchos españoles lograron un marco legal y moral para explotar a los indígenas americanos.

En el texto de la obra, Juan de Castellanos contrapone el mundo cristiano al pagano, pero finalmente lo que tenemos frente a nosotros es un solo mundo. No hay más que un mundo, diría años más tarde el cronista mestizo Garcilaso, "símbolo viviente del encuentro entre los dos mundos" ${ }^{30}$, proponiendo mirar el Viejo y el Nuevo Mundo como un todo.

El mito del imperio universal ${ }^{31}$ es uno de los más persistentes en la historia de Occidente y tiene sus orígenes en las empresas de Alejandro Magno. Bajo Alejandro las tres partes del mundo se encuentran idealmente unificadas en un mismo proyecto político militar cuya vocación es la conquista del mundo entero ${ }^{32}$. A partir del emperador Augusto, los romanos desarrollarían el discurso del poder universal y se propondrían llegar hasta las antípodas.

Lo que encontramos, entonces, en esta obra, tanto en su contenido literario como visual, es la resurrección de ese viejo mito imperial que tiene un nuevo punto de inflexión en la aparición del Sagrado Imperio Romano con Carlos V coronado emperador el año 1519. "La propaganda de 
la monarquía española rescata la idea clásica de un retorno a una edad de paz y justicia bajo un solo soberano, donde el sol jamás se pone" ${ }^{33}$. Felipe II continúa por estos pasos llegando a consolidarse como el "paladín de la Cristiandad", distintivo que se explotará visualmente en varias manifestaciones visuales de la época. Un ejemplo es el grabado de Hans Liefrinck en que Felipe II y el Papa le entregan un globo terráqueo a Cristo. "Cristo y los poderes de la tierra" es el nombre de esta imagen donde se alude a la idea de imperio universal católico, a través de la figura del Papa, quien hiciera cesión de las tierras descubiertas a los Reyes Católicos. La alusión a los descubrimientos se da a través de un segundo plano con mares y embarcaciones que los surcan. Al igual que nuestro emblema, la cruz corona la escena.

El tipo de imperio perseguido por los Austrias es uno católico, en que la defensa de la fe cristiana es el eje principal de la actividad política. La interpretación católica del imperio fue reflexionada profundamente en el libro Razón de Estado (1589) de Giovanni Botero, rápidamente traducido al español por orden de Felipe II en 1593. Como una suerte de respuesta a El Príncipe de Nicolás Maquiavelo, el autor presenta "los medios convenientes para fundar, conservar y engrandecer un señorío" ${ }^{34}$, poniendo en el centro del debate la importancia de la fe para las razones de un buen gobierno. Para ello, observa con buenos ojos la relación un rey y una religión, pues como señala que "la religión es fundamento de todo principado, porque [...] hace al Príncipe amado de Dios", puesto que "la república es casi una viña, que no puede florecer ni dar disfrute, sino [con] la ayuda [de] las influencias del Cielo" ${ }^{35}$.

Esta identidad político-religiosa, además, permeó el discurso sobre la Conquista de América. En este sentido, el imperium o dominio del Nuevo Mundo tuvo un fuerte componente religioso, al punto que, como señala el historiador Jorge Cañizares-Esguerra, los conquistadores se veían en un proceso de liberación de los indígenas "de manos del dominio brutal, implacable y tiránico de Satanás" ${ }^{36}$. De esta manera, este imperio católico, representado en la imagen de Hispania, buscó a través de la cruz, transformar "las «tierras baldías» en florecientes «plantaciones» espirituales" ${ }^{\prime}$. Lo que justificó, además, la llegada de múltiples proyectos misionales asociados a la salvación y deseo por la conquista espiritual de las Indias ${ }^{37}$.

Paul Kleber describe a los Habsburgo como una dinastía con su propia mitología y un fuerte sentido de destino ${ }^{38}$. Hay que recordar también que los Reyes Católicos habían sentado un precedente importante respecto de la relación intrínseca entre unidad religiosa y unidad política, como demostraron con la expulsión de árabes y judíos de España durante su mandato.

El sueño de una España imperial y la utopía de un mundo ordenado bajo los dictámenes del Emperador y la religión universal constituyen una propaganda desde el poder. Estamos hablando de propaganda política que, según Vilá puede leerse como derivada de la Eneida de Virgilio y debidamente enlazada con la doctrina cristiana y con profecías bíblicas que confirman el carácter providencial de las figuras y obra de Carlos V y Felipe II39. Ambos utilizan la figura del héroe y del monarca, como también la del Buen Pastor, como se alude en aquella inscripción del dibujo que habla de esas otras ovejas a las cuales también hay que conducir porque habrá un solo rebaño y un solo pastor. El objetivo de esta obra épica, que muestra su vocación utópica, es lograr un imperio universal y unificado donde reinen la paz y la justicia.

A pesar de que es difícil cotejar el impacto de esta idea en el imaginario y en los corazones de los que no detentaban el poder, la literatura popular es siempre una manifestación cultural donde podemos buscar pistas a este respecto. En un brillante artículo titulado Lazarillo de Tormes y la crítica a la utopía imperial, Carmen Elena Armijo nos proporciona algunas ideas a este respecto. Junto con otros estudiosos de la obra, la autora interpreta la última parte como una sátira al triunfo de la imagen de un rey emperador triunfante, divulgada en la época con fines teo-políti$\cos ^{40}$. En esta postura están de acuerdo también Francisco Rico y James. A Parr, quien, sin señalar el aspecto iconográfico, piensa que la crítica del Lazarillo es claramente a la política imperialista de Carlos V, "un tópico que preocupaba mucho a los humanistas de la época" ${ }^{41}$, pero que cla- 
ramente producía efectos económicos adversos entre la población. En términos más generales debemos pensar que el establecimiento de una sociedad ideal siempre es considerada invivible para algunos componentes de la sociedad. En este caso la crítica surge desde la ironía, la única herramienta posible que "permite consolidar una relación adecuada con la utopía como espacio de liberación y justicia, pero también como espacio crítico contra las falsas promesas de la retórica del poder o de la revolución" ${ }^{42}$.

La segunda coyuntura histórica que explica la aparición de propuestas de unidad en la Europa del siglo XVI se inserta en el contexto de los abusos a que había llegado la iglesia europea en el siglo XVI, con la consiguiente reforma protestante, las guerras de religión y la pérdida de la unidad de la cristiandad. A la añoranza de la idea medieval de una cristiandad unida, el catolicismo se pregunta en el Concilio de Trento por la nueva situación cismática. En un intento por volver a unir fe y razón -el paradigma científico de pansofia-, algunos filósofos reflexionan sobre el estado de las cosas y, bajo el signo de la Reforma y Contra reforma "comienzan a trazar proyectos globales y renovadores a fin de lograr la supervivencia del cristianismo" ${ }^{43}$

En este contexto algunos sueñan con tierras lejanas y con una sociedad ideal, unificada y pacificada. Esas tierras lejanas representan la alteridad, pero también la salvación, por lo que pueden entrar en un mismo sistema de juego de espejos. "El antiguo topo literario de un mundo totalmente opuesto y al mismo tiempo especular ofrece extraordinarios recursos para la nueva mitología, que necesita sustentarse en la epopeya de los grandes descubrimientos geográficos para impactar en el imaginario colectivo" ${ }^{44}$.

El libro de Castellanos muestra en su texto una verdadera pasión por la naturaleza. En esto, comparte el espíritu de una época que muestra su curiosidad frente a especímenes traídos de los viajes de exploración y el desarrollo de la llamada historia natural. Esta buscaba "historiar la naturaleza, es decir, describir, catalogar y clasificar animales, plantas y piedras con un objetivo ambicioso y globalizador" 45 , donde lo exótico y lo raro debían entrar en el sistema conocido. La historia natural se devela por su afán descripti- vo y clasificatorio y los naturalistas de la época, ávidos de noticias y especímenes de las tierras descubiertas, las cuales se incorporan en sus sistemas clasificatorios. La imagen que estamos trabajando comparte ese espíritu y encarna el sistema de comparación del mundo conocido con el recién descubierto y lo lleva a un formato visual. Esta imagen comparte, asimismo, el afán utilitarista de la historia natural que compartían los hombres de ciencia renacentistas en su aproximación a la naturaleza. En el caso de los españoles imbuidos en el proceso de conquista de las tierras americanas, el interés por conocer plantas, animales, minerales y hombres se relaciona con la búsqueda del éxito de la empresa imperial.

Los elementos naturales que conforman los márgenes u orillas de la composición, son representativos del Viejo y Nuevo Mundo respectivamente. En su calidad de elementos naturales, hacen alusión a la idea de paraíso o jardín del edén, la cual evoluciona luego hacia el jardín cercado capaz de contener una idea de mundo, un microcosmos terrenal a imagen del microcosmos universal y "respuesta rotunda de la visión del nuevo orden político y religioso triunfante" ${ }^{46}$.

La naturaleza a los márgenes de las escenas centrales y símbolos que otorgan identidad al mundo propuesto, nos hablan de un mundo antropocéntrico y racional. La naturaleza del Viejo Mundo, así como la nueva que América proporciona a esta idea ideal de mundo global, están ahí para ser parte del proyecto.

Las Elegías de varones Ilustres de Indias plantean un proyecto racional y con pretensión eterna. El tipo de orden social que las Elegías legitiman es uno en que se conquista y subordina lo emocional. Se presenta la conquista como un proceso racional, frente a la barbarie de un indígena que muchas veces se niega a la presencia del español.

\section{Reflexiones finales}

El emblema que acabamos de revisar comparte las características de la Utopía propuesta por Tomás Moro, en el sentido de la vocación histórico temporal que hace de ese lugar supuestamente inexistente un objeto de anhelo para establecer este mundo perfecto. En este aspec- 
to, dice Abellán, la utopía ayuda a la realización temporal del hombre y trata de impulsarle en el mejoramiento de sus condiciones concretas de vida ${ }^{47}$. Prosigue Abellán diciendo que "la utopía es el deseo de salvación eterna, realizado dentro del tiempo, en el despliegue de las posibilidades históricas de cada época". Es este aspecto el que hace de las utopías un verdadero motor histórico y justifica su presencia en diversos formatos y soportes en todas las épocas. Un motor que pretende mejorar el presente para lograr en el futuro un mundo mejor.

A partir del Renacimiento, surgen iniciativas para ordenar el mundo. Al establecer complejos sistemas de ordenamiento, se vislumbra el cometido del hombre europeo de querer ordenarse a sí mismo ${ }^{48}$. El establecimiento de diferencias y similitudes con los otros no están dadas a priori, sino que constituyen una estrategia de conocer y ordenar lo conocido para vivir mejor. El emblema que hemos analizado muestra en forma explícita las diferencias entre el Nuevo y el Viejo Mundo. Sin embargo, hubo otras iniciativas de la época que eligieron colocar a los especímenes del Viejo y del Nuevo Mundo en las mismas categorías, donde las diferencias están dadas por criterios de otra índole. Es el caso, por ejemplo, de los gabinetes de curiosidades, donde los objetos curiosos de todas partes del orbe conviven juntos. Es también el ámbito de los álbumes de naturaleza, donde uno puede leer entre líneas el modelo de clasificación a través del cual se ordena la naturaleza en el siglo XVI ${ }^{49}$. Ahí las opciones de ordenamiento son múltiples y variadas: se pueden mostrar órdenes de lo natural desde las diferentes etapas de la vida de una especie, o las gamas de colores que se dan en la naturaleza o de los tamaños de las especies. En estos álbumes, las cosas del Nuevo Mundo conviven con las de Europa y Asia. Por lo tanto, al enfrentarnos con este orden que el frontispicio de Castellanos nos propone, vemos que lo que tenemos al frente es una propuesta de otro tipo de orden: un orden político ideal donde la descripción de la naturaleza está subordinada a una idea política de vocación utópica. El orden que propone Castellanos no es el que propone una incipiente ciencia en desarrollo en el siglo XVI, sino que es un orden necesario para establecer una sociedad ideal.

A diferencia de la experiencia inglesa en América del Norte, España necesitaba del indígena americano para su utopía. Independiente de las acciones particulares de los conquistadores que abusaron de los indígenas, la Corona los consideró sus vasallos y los incluyó en las leyes intentando legislar en forma justa para ellos. El español, a diferencia del inglés que llevó a su familia Norteamérica, se fundió con el indígena conformando una sociedad nueva. 


\section{NOTAS}

*Para la traducción se utilizó La Sagrada Biblia, (trad. Felix Torres), Imprenta de Miguel de Burgos, Madrid, 1834.

${ }^{1}$ En un subcapítulo denominado "Utopía y Juego", Raymond Ruyer argumenta que en toda utopía se esconde algo de juego, una actividad que aspira a realizarse. Se construye un sistema y el creador juega a ver cómo funciona. Para Ruyer, la actividad de la utopía es, precisamente, una actividad demiúrgica pues se dirige a un mundo, a un universo cerrado. "El utopista actúa como si realmente pudiera crear un mundo completo, con sus instituciones, sus artes, su técnica y su religión. Naturalmente, esto no puede hacerlo más que en el campo del juego", en A. Neusüss, Utopía, Barral Editores, Barcelona, 1971, pp. 167-168. José Carlos Martínez García también considera que Utopía de Tomás Moro es un proyecto lúdico. En J. Martínez García, Historia de la Utopía, del Renacimiento a la Antigüedad, Grupo de estudios del siglo XVIII, Universidad de Salamanca, 2005.

${ }^{2}$ V. Mínguez, "Un imperio simbólico. Cuatro décadas de estudios sobre la escenificación de «La práctica del poder»" en Visiones de un imperio en fiesta (coord. I. Rodríguez y V. Mínguez), Fundación Carlos de Amberes, CasteIlón, 2016, p. 31

${ }^{3}$ Utopía es una palabra de origen griego que etimológicamente puede tener dos acepciones: ou-topía, que significa de ningún lugar (del griego ou: ningún) y eu-topía, que significa el país donde todo está bien (del griego eu: bien), el Estado perfecto.

${ }^{4}$ Slavin J., Arthur, "The American Principle from More to Locke", en First Images of America: The Impact of the New World on the Old (Ed. F. ChiapeIli), University of California Press, 1976, p. 145.

${ }^{5}$ No corresponde a este trabajo hacer una definición del concepto utopía ni de las diferentes interpretaciones que a través del tiempo han aportado a la discusión sobre sus connotaciones e implicancias. Grosso modo la utopía comprende tanto una crítica a la situación contemporánea de las cosas, como el diseño global de una alternativa ideal.
Intentaremos que nuestro objeto de estudio "una alegoría visual del imperio católico universal", devele su vocación de sueño o idea de mundo perfecto, sueño de un verdadero y justo orden de vida, de vocación utópica, como hemos propuesto al comienzo de este trabajo.

${ }^{6}$ M. Gonzáles García y R. Herrera Guillén, Utopía y Poder en Europa y América, Editorial Tecnos, Madrid, 2015, p. 13

${ }^{7}$ B. Fernández Herrero, La Utopía de la aventura americana, Editorial Anthropos, Barcelona, 1994, p. 91

${ }^{8}$ R. M. Serrera, La América de los Habsburgo (1517-1700), Universidad de Sevilla, Sevilla, 2013, p. 102

${ }^{9}$ F. Checa Cremadas, Carolus, Sociedad Estatal para la Conmemoración de los Centenarios de Felipe II y Carlos V, Madrid, 2000, p. 543

${ }^{10} \mathrm{~A}$. Redondo, "Revisitando el concepto de utopía y algunas de sus manifestaciones en la España del siglo XVI y de principios del XVII", Spania, 21 de junio de 2015 [Fecha de consulta: 22 de marzo de 2017].

${ }^{11}$ Redondo, op. cit.

${ }^{12} \mathrm{~S}$. Cro, "La utopía cristiano social en el Nuevo Mundo", Anales de Literatura Hispanoamericana, vol. VI, 7, 1978, pp. 87-129.

$13 \mathrm{~J}$. de Castellanos, Primera Parte de las Elegías de varones ilustres de Indias, Casa de la viuda de Alonso de Gómez, Madrid, 1589.

${ }^{14} \mathrm{~J}$. E. Rojas Otárola, "Poética y Política en la épica renacentista: La influencia clásica en Elegías de varones ilustres de indias, de Juan de Castellanos", Literatura: teoría, historia, crítica, $\mathrm{n}^{\circ} 11$, 2009, pp. 334

${ }^{15}$ Un excelente artículo sobre la admiratio en las crónicas americanas es el de R. Álvarez Moreno, "El admirarse como forma de enfrentar la nueva realidad americana", Anuario de estudios americanos, vol. 61, n², pp. 413-430.

${ }^{16}$ L. Vilá y Tomás, Épica e Imperio. Imitación virgiliana y propaganda política en la épica española del siglo XVI, Tesis doctoral Universitat Autónoma de Barcelona, 2001, p. 9

${ }_{17}$ Hernán Cortés, en Olaya Sanfuentes, Develando el Nuevo Mundo. Imágenes de un proceso, Ediciones Uni- versidad Católica, Santiago de Chile pag 139

${ }^{18}$ A. Gerbi, La disputa del nuevo mundo: historia de una polémica, 17501900, Fondo de Cultura Económica, México, 1960, p. 7

19 J. P. Martínez García, Historia de la Utopía, del Renacimiento a la Antigüedad, Universidad de Salamanca, Salamanca.

${ }^{20} \mathrm{P}$. Mason, Deconstructing America. Repersentation of the Other, Routledge, London and New York, 1990.

${ }^{21}$ Según María Dolores Alonso Rey en un artículo que muestra los usos de la iconografía del árbol en los emblemas españoles, el árbol puede estar presente en un emblema mostrando los recursos naturales y humanos. María Dolores Alonso Rey, "El árbol en los libros de emblemas españoles" en Palabras, símbolos, emblemas. Las estructuras gráficas de la representación (Eds. A. Martínez Pereira, I. Osuna, V. Infantes), Turpin Editores, Sociedad Española de Emblemática, Madrid, 2013, p. 120.

${ }^{22} \mathrm{~A}$. G. Debus, El hombre y la naturaleza en el renacimiento, FCE, México, 1985, p. 96

${ }^{23}$ Vilá, op. cit., p. 228

${ }^{24}$ R. López Torrijos, "Imágenes de Europa en la España moderna" en I Congreso Internacional, V Coloquio del Grupo Europeo de Investigación histórica potestas. Europa: historia, imagen y mito (Coord. J.J. Ferrer Maestro, P. Barceló), Universitat Jaume I, Castelló, 2008, p. 415

${ }^{25} \mathrm{Ibid}, \mathrm{p} .416$

${ }^{26}$ Esta frase se encuentra en latín: "HISPANUM REGNUM DECLARAT BELLICA VIRGO/

EST MARIS OCEANILITUSSO PSE DRACO. /HIC SERPENSIGENS ORBEM CIRCUNDAT UTRIUNQUE /CONIUNGENS CAUDE，PERFRETA， LONGA， CAPUT. / ERGO, QUICQUID ERIR, QUOD CONTINET ORBIS UTERQ /MAGNE PHILIPPE TWO SERVIET IMPERIO" En términos de traducción, en el primer verso se ha decidido optar por bellica virgo como sujeto lógico, en vez de hispanum regnum. Además, en el cuarto, una traducción probable sea "Uniendo la cabeza con su cola, estrecha y larga", sin embargo, es posible separar "per freta longa", omi- 
tiendo la coma, pues da un sentido de circularidad mundial en la época de la circunnavegación del mundo.

${ }^{27}$ Josep Fontana, Europa ante el espejo, Editorial Crítica, Barcelona 2000, pag 10.

${ }^{28} \mathrm{Ibid}, \mathrm{p} .116$.

${ }^{29}$ Serrera, op. cit., p. 144

${ }^{30} \mathrm{~F}$. Cantú, "América y Utopía en el siglo XVI" Cuadernos de Historia Moderna Anejo, vol. 1, 45, 2002, p. 64.

${ }^{31}$ Tradicionalmente, se ha estudiado a la España del Antiguo Régimen bajo el concepto de "monarquía católica", que buscó otorgar una identidad religiosa a los territorios bajo el Estado patrimonial de los reyes españoles. Véase Manuel Fernández Álvarez, España y los españoles en los tiempos modernos, Universidad de Salamanca, Salamnca, 1979, p. 128. Sin embargo, en el presente artículo se ha optado por hablar de un Imperio católico para el siglo XVI que, aunque parte de la misma base identitaria, intenta dar cuenta del ideal expansionista del Estado sobre espacios diversos más allá de sus fronteras tradicionales. Pues tal como lo señalan los historiadores y sociólogos Jane Burbank y Frederick Cooper, los imperios no supusieron una unión espontánea dentro de la diversidad, sino que necesitaron de violencia, coacción y la conformación de una identidad, en este caso católica, para su viabilidad. J. Burbank y F. Cooper, Imperios: Una nueva visión de la Historia universal, Barcelona, Crítica, 2011, pp. 11-19.

${ }^{32}$ El Nuevo Mundo. Problemas y Debates (D. Bonnett y F. Castañeda, eds.), Universidad de los Andes, Bogotá, 2004, p. 33.

${ }^{33} \mathrm{lbid}$.

${ }^{34} \mathrm{G}$. Botero, Razón de Estado con tres libros de la grandeza de las ciudades de Juan Botero traducido del italiano en castellano por Antonio de Herrera, Casa de Sebastián de Cañas, Burgos, 1603, Libro I, 1.

${ }^{35} \mathrm{Ibid}$, Libro II, 47v y 45v-46.

${ }^{36}$ Jorge Cañizares-Esguerra, Católicos y puritanos en la colonización de América, Madrid, Marcial Pons, 2008, p. 18.

${ }^{37}$ Ibid, p. 32

${ }^{38}$ Paul Kleber en Víctor Mínguez p. 253.

${ }^{39}$ Vilá, op. cit., p. 219.
${ }^{40}$ Carmen Elena Armijo, Lazarillo de Tormes y la crítica a la utopía imperial, AISO Actas III (1993) p. 30

${ }^{41}$ Parr en C.E Armijo, p. 30

${ }^{42}$ Moisés González García y Rafael Herrera Guillén, Utopía y Poder en Europa y América, Editorial Tecnos 2016, p. 16

${ }^{43}$ J. C. Martínez García, op. cit.

${ }^{44}$ Ibid, p. 59

$45 \mathrm{~J}$. Pardo Tomás, El tesoro natural de América. Colonialismo y ciencia en el siglo XVI, Nivola Editores, Madrid, 2002.

${ }^{46}$ B. Souviron López, "Arcadia y Nuevo Mundo: un capítulo de la historia de Utopía" Anuarios de estudios americanos, vol. 53, n¹, 1996, p. 19

47 J. L. Abellán, "Prólogo" en Fernández Herrero, op. cit, p. 14

${ }^{48}$ Mary Douglas, Estilos de Pensar. Ensayos Críticos sobre el buen gusto, Editorial Gedisa, Barcelona, 1998, p. 155

${ }^{49}$ F. Egmond, "Ordenar la naturaleza. Álbumes de naturaleza como colecciones. Siglo XV" en una conferencia dictada en el Instituto de Historia de la Pontificia Universidad Católica de Chile, 20 de mayo, 2017 